\title{
"My Plate is Full": Reasons for Declining a Genetic Evaluation of Hearing Loss
}

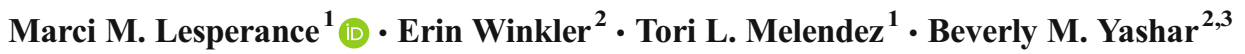

Received: 28 November 2016 / Accepted: 18 August 2017 / Published online: 4 October 2017

(C) National Society of Genetic Counselors, Inc. 2017

\begin{abstract}
The aim of this study was to obtain patient and parent perspectives on genetic evaluation of hearing loss, in order to identify motivators, expectations, and barriers. Three focus groups were conducted following a semi-structured discussion guide, led by an independent moderator. Participants were hearing parents of children with permanent hearing loss or deaf adults. Qualitative content analysis was used to develop a codebook and identify major themes and subthemes. Participant views were compared to national guidelines. The 28 participants comprised 23 parents representing 21 unique families and 5 deaf adults. 13/21 families and 0/5 adults reported comorbidities, $4 / 21$ families and $3 / 5$ adults had a positive family history, and 12/21 families versus $0 / 5$ adults had utilized genetics services. A common theme among adults and parents was a curiosity as to the cause of hearing loss. Parents were motivated to detect comorbidities and optimize care for hearing loss. Some parents felt overwhelmed by the hearing loss and unprepared to pursue early genetic evaluation as recommended in guidelines. Several reported positive experiences following
\end{abstract}

Presented in part at the National Society of Genetic Counselors 32nd Annual Education Conference, October 9-12, 2013, Anaheim, CA and at the Annual Meeting of the Collegium Oto-Rhino-Laryngologicum Amicitiae Sacrum, San Francisco, CA August 23-26, 2015

Marci M. Lesperance

lesperan@med.umich.edu

1 Division of Pediatric Otolaryngology, Department of Otolaryngology-Head and Neck Surgery, University of Michigan Health System, CW-5-702 SPC 4241, 1540 East Hospital Drive, Ann Arbor, MI 48109-4241, USA

2 Genetic Counseling Program, University of Michigan Health System, Ann Arbor, MI, USA

3 Department of Human Genetics, University of Michigan Health System, Ann Arbor, MI, USA genetics consultation, while others reported unease and unmet expectations. Notably, both parents and adults expressed ambivalence regarding the desire for genetic knowledge. Financial concerns and difficulties obtaining a referral were cited as extrinsic barriers. For parents of children with hearing loss, both the presence of comorbidities and a positive family history were drivers of genetics consultation and/or genetic testing. We identified educational opportunities for both patients and providers that would improve informed decision-making and increase access to genetic services. Consideration of the patient/family perspective and their decision-making processes, along with flexibility in the approach to genetics evaluation and its timing, will optimize both the development and implementation of guidelines.

Keywords Deafness $\cdot$ Hearing loss $\cdot$ Patient preferences . Genetic services · Comorbidities · Autonomy

\section{Introduction}

Approximately 1 in 500 babies are born with communicatively significant hearing loss (Kemper and Downs 2000), and early intervention is essential to optimize development of speech and language (C. Yoshinaga-Itano 2003; YoshinagaItano et al. 1998). In 1999, Congress passed legislation that provided funding to states to establish early hearing detection and intervention (EHDI) programs (White 2003). The goal of EHDI was to ensure that all newborns are screened for hearing loss and that newborns who do not pass the screening receive an audiologic diagnosis before 3 months of age, as well as providing for early intervention.

Approximately 50\% of hearing loss is genetic in etiology, and this proportion is likely to increase as environmental causes such as congenital rubella diminish in incidence. 
There are over 400 genetic syndromes that include hearing loss (OMIM 2016), but most childhood hearing loss, approximately $70 \%$ of cases, is non-syndromic or isolated hearing loss (Morton 1991). Non-syndromic hearing loss displays remarkable genetic heterogeneity, with over 90 genes identified (Van Camp \& Smith, 2016). Genetics consultation plays a valuable role in the evaluation of childhood hearing loss in identifying comorbidities and potential syndromes, as well as specifying a molecular genetic etiology (Alford et al. 2014).

In parallel to the increasing number of young children diagnosed with hearing loss through newborn hearing screening, in the year 2000 the American College of Medical Genetics (ACMG) issued a guideline that recommended a genetic evaluation for all children with confirmed permanent hearing loss (ACMG 2000), which was reinforced in 2014 (Alford et al. 2014). In general, the identification of a genetic etiology allows for accurate recurrence chance counseling for future siblings as well as the patient's future offspring and may help support adaptation to the diagnosis by both the child and the family (Biesecker and Erby 2008; Cohen and Biesecker 2010). However, the barriers to genetic testing in this population are similar to those in patients with any inherited disorder, including anxiety about learning information that one might prefer not to know, the questionable reliability of test results, and the potential negative influences of test results on reproductive decision-making (Burton et al. 2006).

For hearing loss in particular, with a growing body of genotype-phenotype correlations, genetic diagnosis may also provide prognostic information regarding progression of hearing loss and guide future management options (Morzaria et al. 2005). A practice survey from 2007 indicated that approximately half of clinicians will refer patients with hearing loss for genetics consultation (Duncan et al. 2007); however, not all parents or patients pursue the referral when it is offered. There are many factors that play into the parental decision to pursue this genetic evaluation, including parental perceptions, family environment, and pediatrician involvement (Palmer et al. 2009).

The patient/parent perspective on genetic evaluation of hearing loss has been investigated in multiple previous studies. Most are survey-based, dating to the early years of genetic testing for hearing loss (Brunger et al. 2000; Dagan et al. 2002; Martinez et al. 2003; Middleton et al. 2001; Middleton et al. 1998; Palmer et al. 2008; Stern et al. 2002; Taneja et al. 2004). Most studies targeted patients seen in the genetics clinic and did not specify whether hearing loss was nonsyndromic versus accompanied by comorbidities. Considering the significant changes in genetic testing for hearing loss, such as the availability of the OtoSCOPE panel in 2011 (Shearer et al. 2010), we sought to understand if the conclusions from these earlier studies are still applicable to the present day or generalizable to adults with hearing loss. Therefore, we conducted 3 focus groups exploring the perspectives of parents of children with hearing loss as well as the perspectives of deaf adults. We included participants who had had genetics evaluation as well as those who had declined or had not had the opportunity for a genetics evaluation. Finally, we explored differences in responses between participants with nonsyndromic versus syndromic hearing loss. We sought to identify current day motivators and barriers to genetic testing and to define the attributes of a genetic evaluation most valued by patients and parents. Our ultimate goal is to improve patient care by helping clinicians understand patients' preferences for a genetics evaluation and to develop a set of best practices that can be incorporated into care guidelines.

\section{Materials and Methods}

\section{Recruitment}

Approval for the study was obtained from the University of Michigan Institutional Review Board (Study Number HUM00056347) with a waiver of documentation of informed consent. Participants were recruited through the otolaryngology clinics at the University of Michigan Health System and the Michigan Hands and Voices support group listserv ("Michigan Hands, and Voices Website," 2010) using a flyer and email blasts. In order to protect participant confidentiality, medical records were not accessed, and all demographic and medical information was only available as volunteered by the participants during the focus groups. Information regarding the age of the individual with hearing loss was not specifically collected.

Eligible participants included adults with hearing loss and parents with at least one child with hearing loss between the ages of 0 and 18 years. All participants communicated in English or in American Sign Language (ASL), with interpreters available as needed. Participants were compensated with $\$ 100$ Visa gift cards obtained through the Human Subject Incentive Payment Office.

\section{Procedures}

Two in-person focus group sessions were conducted with parents, and one was conducted with adult participants. We refer to the adult participants as "deaf adults" since all had profound hearing loss, whereas "hearing loss" is used to describe the children, who had varying degrees of hearing loss. The focus group sessions were moderated by a contracted independent research consultant who followed a semi-structured focus group discussion guide that was developed by the researchers. The session began with an "ice-breaker" period in which participants shared their personal stories of hearing loss, followed by discussion of sources of information and support, 
perceptions and utilization of genetic evaluation and genetic testing for hearing loss, the characteristics of the "ideal" genetic test, and resources for learning about hearing loss and genetics. During the "ice-breaker" part of the session, themes arose that were considered beyond the scope of the current project, including delays in diagnosis of hearing loss, communication options and interventions for hearing loss, coping and grief, and prenatal testing.

Follow up open-ended probes were used to elicit additional information. Each session lasted approximately $2 \mathrm{~h}$. All sessions were audio recorded and transcribed, and two researchers (EW, MML) were present to take notes during each of the focus groups.

\section{Data Analysis}

The transcripts were reviewed by the principal investigator (MML) to correct transcription errors and clarify questions raised by the transcription process. A qualitative content analysis (Saldaña 2012) was performed using Dedoose software, version 5.0.11 (SocioCultural Research Consultants, LLC, Los Angeles, CA) www.dedoose.com. In the first level of reading, two researchers (BMY and MML) reviewed the transcripts to identify topics relevant to the discussions in all 3 focus groups. The code book was then generated from these topics and applied to all 3 focus groups. Two (2) researchers (TLM, BMY) then independently reviewed the transcripts and assigned codes, and discrepancies were resolved.

The code book and the associated content was then sorted by 3 reviewers (BMY, MML, TLM) into appropriate categories and clustered into major themes and subthemes, as described (Saldaña 2012). Representative quotes were selected to illustrate each subtheme, confirming the attribution of each quote in order to ensure that multiple participants' perspectives were represented.

For each family, we coded whether or not they reported undergoing a consultation with a geneticist, genetic testing, or both. Some participants described genetic testing requested by an otolaryngologist or another specialist, such as a cardiologist; if a genetics consultation was not specifically mentioned, we coded the genetics consultation as unknown. Family history and comorbidities were also noted.

\section{Results}

\section{Patient Demographics}

The sample included 28 total participants, of whom 23 were parents representing 21 unique families, and 5 were adults with hearing loss (Table 1). Of the 21 families represented by parents, 13 reported comorbidities in their child with hearing loss, 3 specifically mentioned the lack of comorbidities, and for 5 families, comorbidities were coded as unknown. Four (4) families had 2 children with hearing loss, and 1 of these 4 also had additional relatives with hearing loss. In 3 families, the child with hearing loss was adopted. 12/21 families had pursued genetics consultations and/or genetic testing. All parent participants were hearing.

Of the 5 deaf adults, English was the primary language for 3 participants, and ASL was the primary language for 2 participants. None of the 5 deaf adults reported comorbidities, and 3 deaf adults reported a family history of hearing loss in at least one sibling. None of the deaf adults had undergone genetic testing or had a genetics consultation, either as a child or an adult. 3 of the deaf adults had children, all of whom were hearing.

\section{Major Themes and Subthemes}

Several subthemes emerged from the transcripts, which were coalesced into 3 major themes: Desire for Knowledge, Barriers to Genetic Evaluation and Testing, and Genetics Clinic Experiences.

\section{Desire for Knowledge}

"Desire for Knowledge" (Table 2) was a predominant reason participants expressed interest in a genetics evaluation and genetic testing. Several participants expressed the benefits of detecting comorbidities, with vision concerns the most commonly mentioned. Parents were also clearly motivated to obtain the best care possible for their children, which manifested as a drive to explore every possible avenue of information that could possibly impact their child's future. For many, understanding the cause of their child's hearing loss was felt to influence educational choices or decisions for interventions such as hearing aids.

Additional motivations underlying the "Desire for Knowledge" included family planning, curiosity, altruism, non-hearing related health concerns, and development of the child's sense of identity. Interestingly, many participants were not further able to define their desire for knowledge beyond curiosity or "wanting to know" (Table 2). Participants were interested in genetic testing to help provide answers regarding the etiology of hearing loss, and some parents expressed a desire to better address their child's questions, in particular the reasons why the child has hearing loss.

At the same time, many participants expressed ambivalence about the impact of acquiring genetic knowledge. The prospect of genetic knowledge elicited psychological tension between the potential for increased worry versus the desire to be better prepared and have better understanding. In fact, some comments suggested that pursuing a genetic evaluation could be perceived as a failure to accept the 
Table 1 Demographic information

\begin{tabular}{|c|c|c|c|c|c|}
\hline Family ID & Participants & $\begin{array}{l}\text { Relatives with } \\
\text { hearing loss }\end{array}$ & Comorbidities $^{\mathrm{a}}$ & $\begin{array}{l}\text { Genetics } \\
\text { consultation }\end{array}$ & $\begin{array}{l}\text { Genetic } \\
\text { testing }\end{array}$ \\
\hline 100 & Parent (F) & 1 child & EVA; possible Pendred syndrome & Yes & Yes \\
\hline 103 & Parent $(\mathrm{F})$ & 1 child & Gastrostomy tube dependence & Yes & Yes \\
\hline 105 & Parent (F) & 1 child & Congenital heart disease & Yes & Yes \\
\hline 109 & Parent $(\mathrm{F})$ & 2 children & EVA; Pendred syndrome & Unknown & Yes \\
\hline 119 & Parent $(\mathrm{F})$ & 1 child & Vision problem, prematurity (26 weeks) & Yes & Yes \\
\hline 120 & Parent (M) & 1 child & $\begin{array}{l}\text { Hypotonia, cognitive delay, possible fetal } \\
\text { alcohol syndrome }\end{array}$ & No & No \\
\hline 121 & Parent (F) & 1 child & Fetal hydrops, sensory processing disorder & Unknown & Yes \\
\hline 124 & Parent $(F)$ & 1 child & Heart defect, feeding tube dependence & Yes & No \\
\hline 125 & Parent $(\mathrm{F})$ & 1 child & Clinical diagnosis of Waardenburg syndrome & Yes & Yes \\
\hline 126 & Parent $(\mathrm{F})$ & 1 child & Dystonia, heart defect & Yes & Yes \\
\hline 101 & Parent $(\mathrm{F})$ & 1 child & Cerebral palsy & No & No \\
\hline 104 & Parent $(\mathrm{F})$ & 1 child & Brain damage & No & No \\
\hline 102 & Parent $(\mathrm{F})$ & 2 children & EVA & No & No \\
\hline 114 & Parent $(\mathrm{F})$ & 2 children & No & Yes & Yes \\
\hline 122 & Parent $(\mathrm{F})$ & 1 child & No & No & No \\
\hline 107 & Parent (M) & 1 child & No & Unknown & Yes \\
\hline 106 & Parents $(\mathrm{F}, \mathrm{M})$ & 1 child & Unknown & No & No \\
\hline 108 & Parent $(F)$ & 1 child & Unknown & No & No \\
\hline 110 & Parent (F) & 2 children, both maternal grandparents & Unknown & No & Yes \\
\hline 112 & Parents $(\mathrm{F}, \mathrm{M})$ & 1 child & Unknown & No & No \\
\hline 123 & Parent $(F)$ & 1 child & Unknown & No & No \\
\hline 115 & Deaf adult (F) & Participant and sibling & Unknown & No & No \\
\hline 116 & Deaf adult (M) & Participant and his sibling & Unknown & No & No \\
\hline 117 & Deaf adult $(\mathrm{F})$ & Participant & Unknown & No & No \\
\hline 118 & Deaf adult (F) & Participant & Unknown & No & No \\
\hline 111 & Deaf adult (F) & Participant and her sibling & Unknown & No & No \\
\hline
\end{tabular}

${ }^{a}$ as reported by participants since medical records were not reviewed

$\mathrm{EVA}=$ enlarged vestibular aqueduct

diagnosis of hearing loss, or even a failure of accepting their child as he/she is (Table 2).

In contrast to ACMG guidelines (Alford et al. 2014), some parents preferred to defer a genetic evaluation until their child was of an age to decide for herself or himself, while acknowledging the potential value of the information (Table 2). Interestingly, while some of the deaf adults agreed with waiting, others expressed an opposing preference and wished that their parents had obtained this information on their behalf when they were children (Table 2). These adults expressed no concerns with the concept of their parents having made this decision for them during childhood. It should be noted that none of the deaf adults had had genetic testing as a child, which is not surprising given that genetic testing for hearing loss was not widely available 20 or more years ago. Although they expressed curiosity as to the cause of hearing loss, none had pursued a genetic evaluation as an adult.

\section{Barriers to Genetic Evaluation}

The second major theme concerned "Barriers to Genetic Evaluation" (Table 3). Some barriers were extrinsic and thus independent of the participant's desire to pursue evaluation, such as difficulty with obtaining a referral or scheduling the genetics evaluation, or financial concerns related to insurance coverage. Nearly half (12/21) of the parents had pursued a genetics evaluation, suggesting that extrinsic barriers were not uniformly insurmountable. Financial considerations were cited as impacting the decision to pursue genetic testing after discussion with the geneticist. Referrals to the genetics clinic came from a variety of providers, including otolaryngology, primary care providers, and other specialists (such as cardiology), in the cases where children were seeing multiple physicians. Audiologists were seen as a source of information, but many participants expected the genetics 
Table 2 Desire for Knowledge with associated subthemes

Detect comorbidities

Some of the syndromes have other complications and I thought, well, if I waited that long or if I didn't know about her hearing, what if her eyes are next?

There may be other things that you can do to help the child if you did know - I mean the other areas that you would need to watch for, things that could be changing, too.

I want them to test for things that may have an impact. If I know my son is going to likely lose his eyesight along with being deaf then that might be [a] push more in the camp of, yeah I think I do want to pursue a cochlear implant for him because he's not going to have visual access to sign language as he gets older.

Prepare for and optimize child's future

Our son had gone through such a hard time getting diagnosed that I felt like I wanted to make sure we were on top of it with him and that he wouldn't have to go down the same road that [our older child, Bobby] had been down. So by doing the genetic testing, our sole purpose was just to determine if there was a genetic component and, if so, so that we could help our child that was on the way.

Paving a path that's best for your children I think is important and that's the purpose of it.... If you know ahead of time that potentially you're going to lose your vision then, yeah, that helps you create a direction for your child, whether you're going to grow up in a Deaf culture or not. ... You want your child to learn the best that they possibly can with whatever needs you can provide for them. Yeah, as much genetic testing can done, I'm all for it.

And that way maybe you can help your child because if you know other kids have this, now you know a way to teach them better. Maybe they pick up on sign language faster or they pick up on reading lips so you kind of gear towards that to try to help them to progress as best as possible.

\section{Wanting to know}

I work in a scientific background and I just want to know why. I mean I understand that it may not change the path but I just love that knowledge. I want to know.

I did want to know, is there a gene that he has that has either a connection with the congenital heart defect and hearing loss, or hearing loss, because for his future, he's going to have these questions. He's starting to ask these questions ... 'why me? Why this? Why that?' I want to have answers for him. So I'm trying to pursue every route I can.

He's going to be someday asking, "Why am I deaf?" Short of an "I don't know" - you know every family has different beliefs, or a "God made you that way" type of an answer, I think I feel like being able to tell him the scientific reason why he's deaf the same way that I can say to my biological daughter you have blue eyes because genetically this is what happened....For me I kind of feel like genetic testing gives him some answers to those identity questions, that it's just the foundation for something that really costs me very little.

\section{Ambivalence regarding knowledge}

Yeah, it's hard. It's like you want to know, but it's scary, too... there may be other things that you can do to help the child if you did know.

She seems so perfect and I don't really care about a test. Then again I would like to get information so if she has questions for me later I can say [what] this is...

For some people it's just being prepared and for other people it would mean okay, you have to worry about this for so long and this could happen or if it never happens you're still going to worry a lot of the time.

Genetic testing, we decided against that. I mean, it wouldn't have affected our decision to have children or not. We wanted a child no matter what. If we had done it, the only reason would be to mentally prepare ourselves. On the other hand, there [are] so many resources out there. Children now are better off than I was.

Timing of genetics evaluation

If it can answer a lot of questions, then I would definitely do it, but there's so [many] unknowns right now that maybe I will wait until they're grown up and ...maybe then we'll have a lot more questions that they can answer.

We feel if they want to pursue it and have that knowledge for themselves, then we will support that for them, but we don't feel like it's a big issue for our family right now.

When they get to the point if they want to know, there will probably be a lot more options out there for them to get tested too. I would have done it because I'm curious why or how I became deaf. ...I kind of wish my parents did it just so I would know. My opinion is that I think parents could go ahead and test and figure out why they became deaf so maybe they could help them with their language development.

Wait and let them make the decision. Without them even knowing what's going on, when they are old enough they can decide themselves.

100 , parent

119 , parent

125 , parent

109 , parent

120 , parent

124, parent

122 , parent

105 , parent

125 , parent

119, parent

112, parent

117 , adult

115 , adult

107 , parent

108 , parent

102, parent

115 , adult

118, adult

116 , adult 
Table 3 Barriers to Genetic Evaluation and Testing

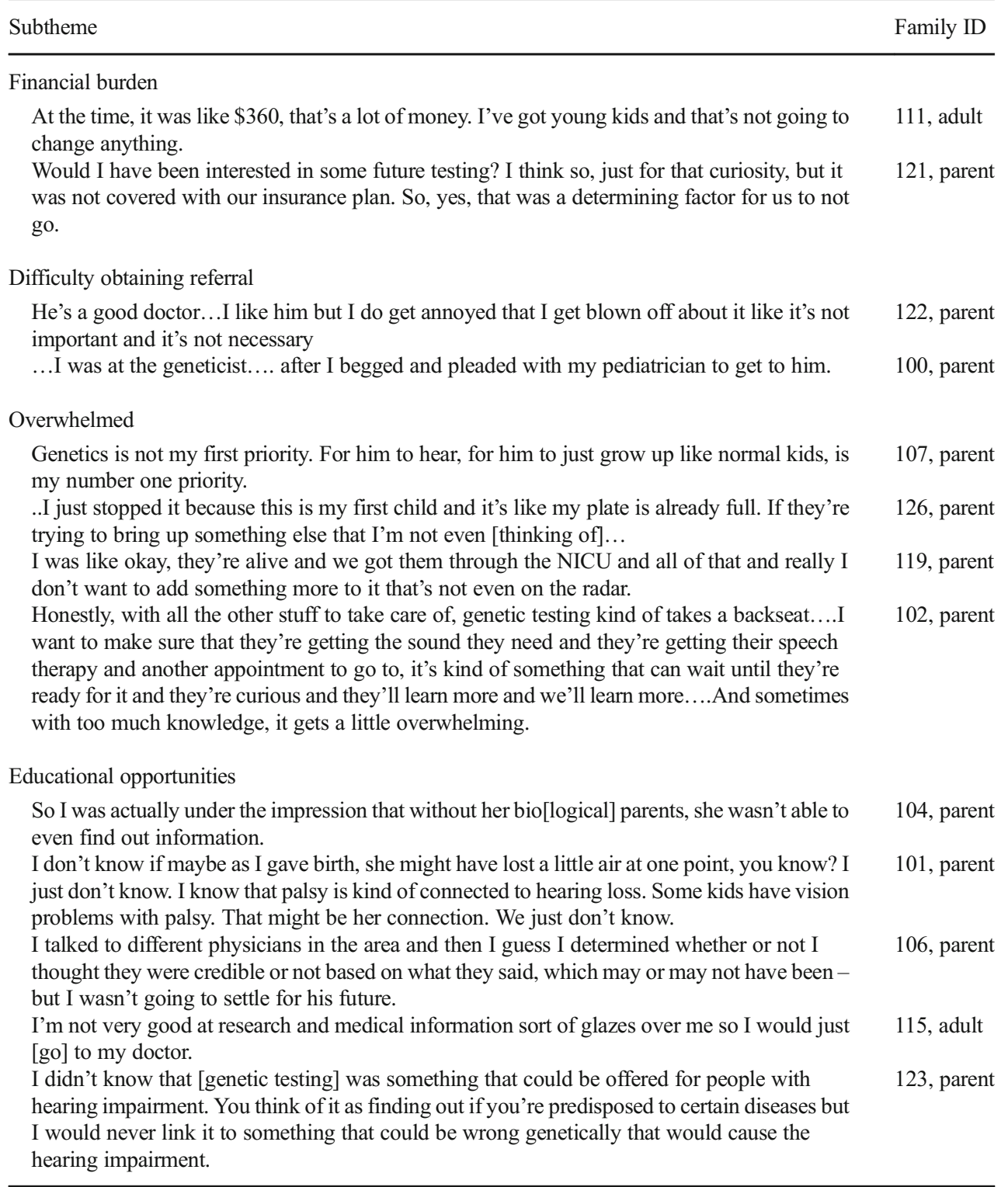

referral to come from their otolaryngologist and not from their primary care physician.

We also identified intrinsic barriers that were personal to the individual participant. Being overwhelmed by their child's hearing loss was a strong theme, and these parents felt they were already dealing with more issues than they could handle (Table 3). Many parents described a long diagnostic odyssey before their child was accurately diagnosed with hearing loss, recounting a struggle to obtain the necessary intervention for their child. As the counterpoint to the participants who expressed a desire for knowledge to discover comorbidities (Table 2), these parents expressed reluctance to discover additional problems that might require their attention or cause more worry. For these parents, genetics consultation and genetic testing were simply not priorities (Table 3 ).
Finally, discussion regarding potential barriers to genetic evaluation revealed opportunities for improving education regarding the process and benefits of a genetics evaluation. In general, participants were not informed regarding the utility of diagnostic testing in the absence of a family history (Table 3). Some formed their own conclusion that the hearing loss resulted from acquired causes unrelated to genetics (Table 3). Some participants could not perceive any apparent value of genetic information if it would not affect immediate medical care or impact family planning decisions.

\section{Genetics Clinic Experiences}

The parents' descriptions of their genetics clinic experiences constituted the third major theme, "Genetics Clinic 
Table 4 Genetics Clinic Experience and Subthemes

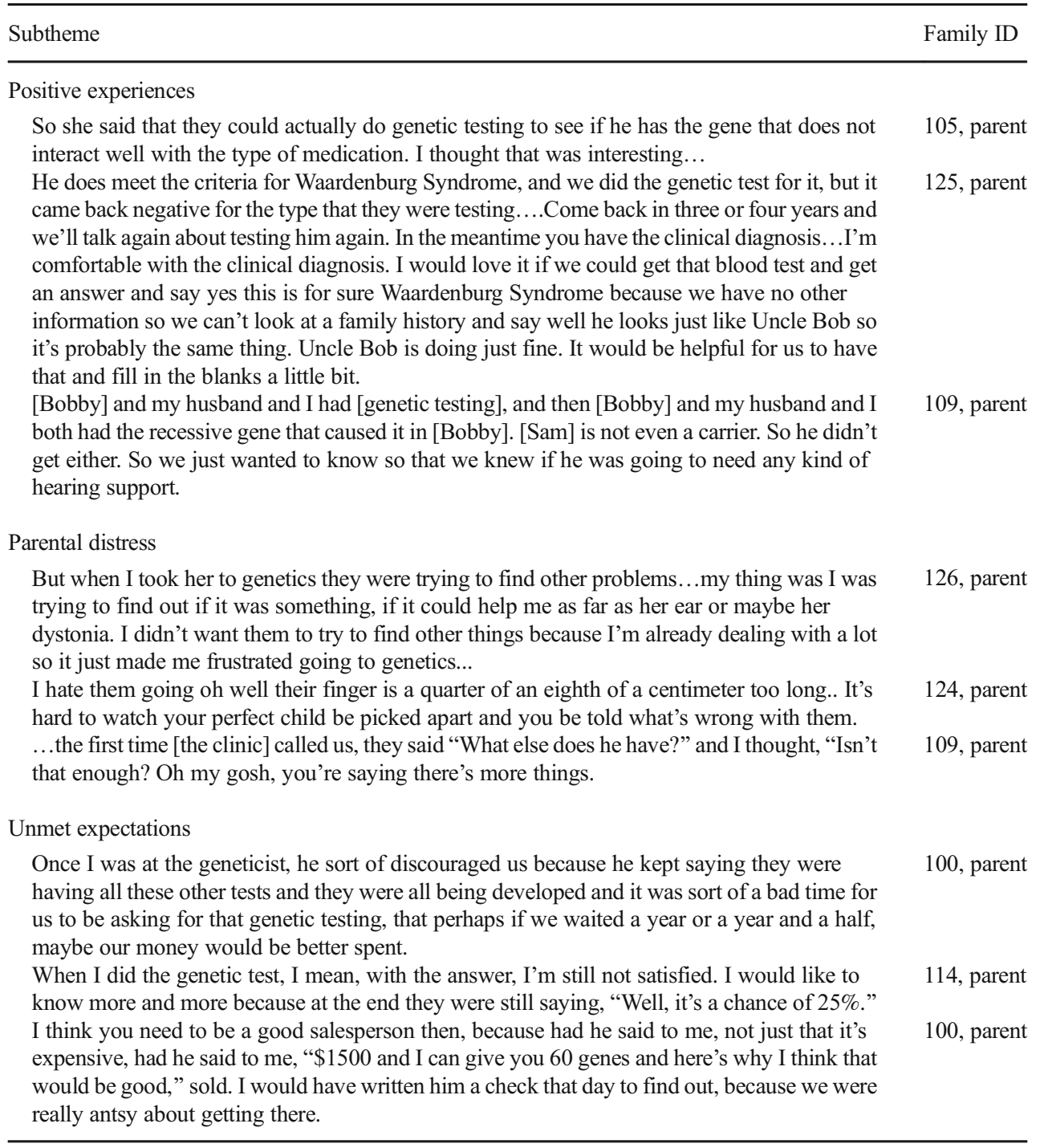

Experiences" (Table 4). Many parents offered realistic descriptions of the evaluation process and manifested a good understanding of the genetics of hearing loss. Regardless of whether a definitive clinical or genetic diagnosis could be made, many parents described positive experiences and understood when to return for further evaluation in the future. On the other hand, some respondents experienced distress with the evaluation, either due to a feeling of unease during the dysmorphology examination, or due to unmet expectations. The identification of pertinent physical findings was sometimes perceived as a criticism or as pointing out imperfections, and parents did not understand how the physical findings were relevant to their child's hearing loss. One participant indicated that the genetics clinic did not appear receptive or accustomed to evaluating a child with isolated hearing loss (Table 4).

Some parents described a significant investment of time and effort to obtain the genetics consultation, only to experience disappointment and unmet expectations. Parents were frustrated and felt directed toward one option, such as deferring testing in the hope of a better and more cost-effective future test, when their immediate desire was to obtain testing. The lack of a definitive answer was discouraging to some parents who were interested in pursuing additional testing beyond what was currently clinically available.

\section{Impact of Comorbidities and Family History}

We examined the impact of comorbidities on the likelihood of pursuing genetics evaluation and/or genetic testing (Table 1). As mentioned above, 13/21 families reported comorbidities in their children with hearing loss, and for the other 8 , comorbidity status was reported as negative or unknown. 4 of 13 with comorbidities had signs of a hearing loss syndrome (Waardenburg syndrome or enlarged vestibular aqueduct/ 
Pendred syndrome), and 3 of these 4 had undergone genetic evaluation and/or genetic testing. Of the 9 other children with comorbidities, 6 of the 9 had undergone either genetics evaluation and/or genetic testing.

With regard to family history, 4 of the 21 families reported having 2 children with hearing loss. Three (3) of these 4 families had pursued either a genetics consultation and/or genetic testing. Thus, among the parents of children with hearing loss, both the presence of comorbidities and a family history were drivers of genetics consultation and/or genetic testing. However, a family history of hearing loss did not appear to influence the deaf adults in seeking genetics evaluation. None of the deaf adults had had genetics consultation or genetic testing, although 3 of the 5 deaf adults had a sibling with hearing loss.

\section{Discussion}

Utilizing focus groups in an open-ended and thorough exploration of the values associated with a genetic evaluation of hearing loss, we were able to identify novel themes as well as enduring ones. Previous studies explored the general topics of genetics, newborn hearing screening, and molecular newborn screening with students at Gallaudet University and parents of children with hearing loss who had been evaluated in a genetics clinic (results reported in two publications (Burton et al. 2006; Withrow et al. 2008)). Other studies involved deaf adults, hearing individuals, and parents of deaf children focused on self-identity and experiences of being Deaf as well as the possible use of genetic testing for prenatal diagnosis or termination of pregnancy (Guillemin and Gillam 2006). Now that advances in genetic testing have made it possible to define the molecular basis of hearing loss in an increasing number of patients, it is possible to explore the rationale that supports real world decision making, which is the unique perspective offered by our study.

We included individuals with long-established diagnoses of hearing loss who reported on their actual behaviors in deciding to pursue or not pursue a genetics evaluation. We believe this approach yields better insights into clinical decisionmaking than posing hypothetical questions, such as whether or not individuals would consider genetic testing if they had a newborn with hearing loss (Martinez et al. 2003). In addition, our study offers a broader perspective than most previous studies by including participants (deaf adults and parents of children with hearing loss) who did not seek genetics evaluation. Participants in this study were recruited from otolaryngology/audiology clinics and support groups rather than from genetics clinics. As noted by Middleton et al. (Middleton et al. 2010), engagement with deaf people is critical in considering questions of genetics and deafness, and therefore our study included deaf adults to represent diverse communication methods and provide perspectives across the lifespan.

In 2007, Steinberg et al. used semi-structured interviews with parents who had been referred but had not completed genetics evaluation, finding that parents were motivated to pursue genetic testing as a key step in learning more information about the cause and origin of their child's hearing loss. Genetic testing was seen as a way to help prepare themselves and their families for future children with hearing loss (Steinberg et al. 2007). Similar to our findings, this study also identified knowledge gaps that represent opportunities to educate patients so that they can make informed decisions regarding genetic evaluation. It has been noted that deaf people have less access to health-related information because public health messages are often transmitted through media only accessible to hearing individuals (Middleton et al. 2010). We found that participants have their own preconceptions regarding genetics, such as assuming that hearing loss cannot be genetic in the absence of other affected family members, or assuming that genetics evaluation cannot be done for an adopted child. In addition, the participants may have their own explanations for the etiology of hearing loss, such as birth trauma or postnatal infection. Studies of parents receiving chromosome microarray results noted similar contradictions in how parents interpreted genetic information, including inaccurate understanding of variants of uncertain significance as diagnostic and an explanation for their child's medical problems (Kiedrowski et al. 2015). As expressed by Mulley et al. (2012), the misdiagnosis of patient preferences has as much potential to cause harm as the misdiagnosis of the patient's medical problem. In order for patients to express their true treatment or outcome preference, they must be informed of all options.

Multiple related studies that focused on the perspective of parents of children with hearing loss presenting to the genetics clinic found generally positive attitudes towards genetic testing for hearing loss (Burton et al. 2006; Duncan et al. 2007; Fisher et al. 2011; Kaimal et al. 2007; Ross et al. 2013). Similar themes regarding desire for knowledge were elicited from the parents in our focus groups and highlight the positive attributes associated with understanding the genetic basis of hearing loss. However, our findings also suggest that the genetics clinic may be less accessible to children with isolated deafness or deaf adults. For deaf adults, there is a paucity of specialized clinics equivalent to those for cancer genetics/ genetic counseling or for prenatal genetic counseling through an obstetrics clinic. Like many overburdened pediatric specialty clinics, the pediatric genetics clinic may need to prioritize access for patients with more severe health problems (Hammers 2009; Kaye 2012). While genetic testing may be done outside of the genetics clinic, patients have an on-going need to access genetic counseling services, which usually requires a visit to the genetics clinic. 
Although there was a strong theme among parents of children with multiple medical problems of feeling overwhelmed, also noted by Steinberg et al. (2007), many of these parents had in fact pursued genetics evaluation. The uptake of genetics services likely depends on whether or not a referral is offered, and/or whether or not the referral is pursued by the patient. Even though the majority of childhood hearing loss is nonsyndromic, primary care physicians or specialists may be more likely to initiate a genetics referral for children with multiple comorbidities than for children with isolated hearing loss. Educational efforts directed at primary care physicians have emphasized the importance of considering a genetics evaluation for patients with multiple congenital anomalies. "Genetics red flags" have been developed to assist in the identification of individuals and families at increased risk of a genetic diagnosis (Genetics in Primary Care Institute Website," 2015; Whelan et al. 2004). However, the fact that a genetics evaluation is indicated for any child with permanent hearing loss may not have been as clearly communicated to the primary care community. Our participants suggested that their primary care physicians deferred consideration of a genetics referral for hearing loss to the otolaryngologist. As the specialists most qualified to identify hearing loss as a permanent and possibly genetic condition, otolaryngologists should be able to discuss the option of a genetic evaluation with their patients. Defining specialty-specific "genetics red flags" for otolaryngologists may be helpful in this regard.

The question remains: when is the right time for a genetics evaluation? Some parents may wish to see the geneticist as soon as the diagnosis of hearing loss is made, while others may need more time to come to terms with the diagnosis of hearing loss and to overcome initial feelings of shock and grief (McAllister et al. 2007; C Yoshinaga-Itano and Abdala de Uzcategui 2001). Many parents opted to defer a decision until more information could be obtained at some future indeterminate date, until their child could decide as an adult, or until new advances in diagnosis or intervention increased the value of the genetics information for them. Some deaf adults agreed with this approach, while others expressed a wish that their parents had pursued genetic testing. Taking a flexible approach to the timing of a genetic evaluation, also recommended by Steinberg et al. (2007), defines a clear role for the managing otolaryngologist or the primary care physician that respects the autonomy of the patient. The provider should be prepared to adapt to the patients' needs at the time, and to provide resources for use at a later date.

The findings of this study are limited by the sample size and the potential for bias due to self-selection, which may have led to a higher proportion of patients with comorbidities than expected. Larger studies have identified cultural affiliation as a predictor of motivations for genetic testing (Boudreault et al. 2010). However, we did not specifically ascertain cultural affiliation in our participants, and affiliation cannot be inferred or assumed from communication method alone (Boudreault et al. 2010). While the focus group format allowed us to accommodate more participants than would have been possible with one-on-one interviews, it also creates a situation where individual participants may have had less opportunity to give their opinion. Patient information was self-reported, and medical records were not accessed. We did not control for the duration of time since diagnosis of hearing loss or genetic evaluation, which may have led to recall bias. Participants were recruited from Michigan and northern Ohio, and the results may not generalizable to a larger population.

Remarkable advances in understanding the etiology of hearing loss have occurred in recent years, with over 90 genes known to be involved in hearing loss [Smith and Van Camp, 2016]. This remarkable genetic heterogeneity adds additional complexity to the process of genetic testing for hearing loss, which will only increase as more genes are discovered. With the onset of next generation sequencing technology, several multi-gene panels for hearing loss have been developed that will allow more patients to receive a timely molecular diagnosis at lower cost. Thus, the growing complexity of genetic information and the higher likelihood of identifying a genetic etiology for hearing loss will make the utilization of genetics services increasingly important. Our study brings the current literature up to date and provides insight into the uptake of genetics services 15 years after the ACMG first issued guidelines that recommended genetics evaluation (ACMG 2000). Among the families and patients with hearing loss who participated in our study, 12/26 (46\%) pursued genetics evaluation, whichhighlights the importance of identifying opportunities to improve implementation of these guidelines. To this end, we provide the following recommendations.

Recommendations:

1. Educate primary care physicians and otolaryngologists regarding indications for genetics referral, so that they may be a resource for participants to make informed decisions, and provide referrals for patients that elect to pursue it.

2. Guideline and policy development should take into consideration the perspective of the patient/consumer, and provide flexibility in terms of the timing of genetics evaluation.

3. Education directed to deaf adults and parents of children with hearing loss needs to address knowledge gaps and employ various communication strategies to make this information accessible to a diverse population.

4. Genetics clinics should take steps to explain the purpose of the detailed physical examination, particularly for patients with nonsyndromic hearing loss, who may not see themselves as "typical" genetics patients. 
5. Clinicians should take care to determine the family's goals and provide information while remaining non-directive in their approach. The diagnosis of hearing loss and/or the technical aspects of genetic information may be overwhelming for parents and adult patients alike.

\section{Conclusion}

Our results suggest that the decision to pursue a genetic evaluation and genetic testing is complex and impacted by multiple factors. These findings highlight the important role that healthcare providers can play in ensuring that families have time to fully explore perceived barriers to testing. In the future, the development of evidence-based guidelines would help facilitate this recommended care by providing topics that providers should cover with patients and families.

Acknowledgements The authors thank the families for their participation. This research was supported by a grant to MML from the American Society of Pediatric Otolaryngology and the American Academy of Otolaryngology-Head and Neck Surgery Foundation. We thank David Baker of Baker Strategy Group for assistance with recruiting and running the focus groups, and Transcription America for assistance with transcription. This study was completed in partial fulfillment of the requirements for Master of Science, University of Michigan Genetic Counseling Program, Ann Arbor, Michigan.

Funding Information Supported by funding from the American Society of Pediatric Otolaryngology and the American Academy of Otolaryngology Head and Neck Surgery Foundation.

\section{Compliance with Ethical Standards}

Conflict of Interest Marci M. Lesperance, Erin Winkler, Tori L. Melendez and Beverly M. Yashar declare that they have no conflict of interest.

Human Studies and Informed Consent All procedures followed were in accordance with the ethical standards of the responsible committee on human experimentation (institutional and national) and with the Helsinki Declaration of 1975, as revised in 2000 (5). Informed consent was obtained from all patients for being included in the study.

Animal Studies No animal studies were carried out by the authors for this article.

\section{References}

ACMG. (2000). American College of Medical Genetics. Statement of the American College of Medical Genetics on universal newborn hearing screening. Genetics in Medicine, 2, 149-150.

Alford, R. L., Arnos, K. S., Fox, M., Lin, J. W., Palmer, C. G., Pandya, A., Rehm, H. L., Robin, N. H., Scott, D. A., \& Yoshinaga-Itano, C. (2014). American College of Medical Genetics and Genomics guideline for the clinical evaluation and etiologic diagnosis of hearing loss. Genetics in Medicine, 16(4), 347-355.
Biesecker, B. B., \& Erby, L. (2008). Adaptation to living with a genetic condition or risk: A mini-review. Clinical Genetics, 74(5), 401-407.

Boudreault, P., Baldwin, E. E., Fox, M., Dutton, L., Tullis, L. E., Linden, J., Kobayashi, Y., Zhou, J., Sinsheimer, J. S., Sininger, Y., Grody, W. W., \& Palmer, C. G. S. (2010). Deaf adults reasons for genetic testing depend on cultural affiliation: Results from a prospective, longitudinal genetic counseling and testing study. Journal of Deaf Studies and Deaf Education, 15, 209-227.

Brunger, J. W., Murray, G. S., O'Riordan, M., Matthews, A. L., Smith, R. J., \& Robin, N. H. (2000). Parental attitudes toward genetic testing for pediatric deafness. The American Journal of Human Genetics, 67(6), 1621-1625.

Burton, S. K., Withrow, K., Arnos, K. S., Kalfoglou, A. L., \& Pandya, A. (2006). A focus group study of consumer attitudes toward genetic testing and newborn screening for deafness. Genetics in Medicine, 8(12), 779-783.

Cohen, J. S., \& Biesecker, B. B. (2010). Quality of life in rare genetic conditions: A systematic review of the literature. American Journal of Medical Genetics. Part A, 152a(5), 1136-1156.

Dagan, O., Hochner, H., Levi, H., Raas-Rothschild, A., \& Sagi, M. (2002). Genetic testing for hearing loss: Different motivations for the same outcome. American Journal of Medical Genetics, 113(2), 137-143.

Duncan, R. D., Prucka, S., Wiatrak, B. J., Smith, R. J., \& Robin, N. H. (2007). Pediatric otolaryngologists' use of genetic testing. Archives of Otolaryngology - Head \& Neck Surgery, 133(3), 231-236.

Fisher, H. R., McKevitt, C., \& Boaz, A. (2011). Why do parents enroll their children in research: A narrative synthesis. Journal of Medical Ethics, 37(9), 544-551.

Genetics in Primary Care Institute Website (2015). geneticsinprimarycare.aap.org. Web. 1 Oct. 2015, from geneticsinprimarycare.aap.org.

Guillemin, M., \& Gillam, L. (2006). Attitudes to genetic testing for deafness: The importance of informed choice. Journal of Genetic Counseling, 15(1), 51-59.

Hammers, E. (Ed.). (2009). Innovations in service delivery in the age of genomics workshop summary. Washington, D.C.: National Academies Press.

Kaimal, G., Steinberg, A. G., Ennis, S., Harasink, S. M., Ewing, R., \& Li, Y. (2007). Parental narratives about genetic testing for hearing loss: A one year follow up study. Journal of Genetic Counseling, 16(6), $775-787$.

Kaye, C. I. (2012). Genetic service delivery: Infrastructure, assessment and information. Public Health Genomics, 15(3-4), 164-171.

Kemper, A. R., \& Downs, S. M. (2000). A cost-effectiveness analysis of newborn hearing screening strategies. Archives of Pediatrics and Adolescent Medicine, 154(5), 484-488.

Kiedrowski, L.A., Owens, K.M., Yashar, B.M., Schuette, J.L. (2016). Parents' perspectives on variants of uncertain significance from chromosome microarray analysis. Journal of Genetic Counseling, 25(1), 101-111.

Martinez, A., Linden, J., Schimmenti, L. A., \& Palmer, C. G. (2003). Attitudes of the broader hearing, deaf, and hard-of-hearing community toward genetic testing for deafness. Genetics in Medicine, 5(2), 106-112.

McAllister, M., Davies, L., Payne, K., Nicholls, S., Donnai, D., \& MacLeod, R. (2007). The emotional effects of genetic diseases: Implications for clinical genetics. American Journal of Medical Genetics Part A, 143(22), 2651-2661.

Michigan Hands \& Voices Website (2010). http://www.mihandsandvoices. org/contact.html. 2016. http://www.mihandsandvoices.org/contact. $\mathrm{html}$.

Middleton, A., Hewison, J., \& Mueller, R. F. (1998). Attitudes of deaf adults toward genetic testing for hereditary deafness. American Journal of Human Genetics, 63(4), 1175-1180. 
Middleton, A., Hewison, J., \& Mueller, R. (2001). Prenatal diagnosis for inherited deafness-what is the potential demand? Journal of Genetic Counseling, 10(2), 121-131.

Middleton, A., Emery, S. D., \& Turner, G. H. (2010). Views, knowledge, and beliefs and genetics and genetic counselling among deaf people. Sign Language Studies, 10, 170-196.

Morton, N. E. (1991). Genetic epidemiology of hearing impairment. Annals of the New York Academy of Sciences, 630, 16-31.

Morzaria, S., Westerberg, B. D., \& Kozak, F. K. (2005). Evidencebased algorithm for the evaluation of a child with bilateral sensorineural hearing loss. The Journal of Otolaryngology, 34(5), 297-303.

Mulley, A. G., Trimble, C., \& Elwyn, G. (2012). Stop the silent misdiagnosis: patients' preferences matter. $B M J, 345$, e6572.

OMIM (2016). Online Medelian Inheritance in Man. OMIM is a comprehensive authoritative compendium of human genes and genetic phenotypes that is freely available and updated daily. http://www. ncbi.nlm.nih.gov/omim. Accessed 21 Nov 2016.

Palmer, C. G., Martinez, A., Fox, M., Sininger, Y., Grody, W. W., \& Schimmenti, L. A. (2008). Ethnic differences in parental perceptions of genetic testing for deaf infants. Journal of Genetic Counseling, 17(1), 129-138.

Palmer, C. G., Lueddeke, J. T., \& Zhou, J. (2009). Factors influencing parental decision about genetics evaluation for their deaf or hard-ofhearing child. Genetics in Medicine, 11(4), 248-255.

Ross, L. F., Saal, H. M., David, K. L., \& Anderson, R. R. (2013). Technical report: Ethical and policy issues in genetic testing and screening of children. Genetics in Medicine, 15(3), 234-245.

Saldaña, J. (2012). The coding manual for qualitative researchers. Thousand Oaks: Sage.

Shearer, A.E., DeLuca, A.P., Hildebrand, M.S., Taylor, K.R., Gurrola, J., Scherer, S., Scheetz, T.E., Smith, R.J.H. (2010). Comprehensive genetic testing for hereditary hearing loss using massively parallel sequencing. Proceedings of the National Academy of Sciences, 107(49), 21104-21109.
Steinberg, A. G., Kaimal, G., Bain, L., Krantz, I., \& Li, Y. (2007). Parental narratives on genetic testing for children with hearing loss: A qualitative inquiry. American Journal of Medical Genetics. Part A, $143 a(14), 1533-1545$.

Stern, S. J., Arnos, K. S., Murrelle, L., Welch, K. O., Nance, W. E., \& Pandya, A. (2002). Attitudes of deaf and hard of hearing subjects towards genetic testing and prenatal diagnosis of hearing loss. Journal of Medical Genetics, 39(6), 449-453.

Taneja, P. R., Pandya, A., Foley, D. L., Nicely, L. V., \& Arnos, K. S. (2004). Attitudes of deaf individuals towards genetic testing. American Journal of Medical Genetics. Part A, 130a(1), $17-21$.

Van Camp G, Smith RJH. (2016). Hereditary Hearing Loss Homepage.URL: http://hereditaryhearingloss.org accessed 2016

Whelan, A. J., Ball, S., Best, L., Best, R. G., Echiverri, S. C., Ganschow, P., et al. (2004). Genetic red flags: Clues to thinking genetically in primary care practice. Primary Care; Clinics in Office Practice, 31(3), 497-508.

White, K. R. (2003). The current status of EHDI programs in the United States. Mental Retardation and Developmental Disabilities Research Reviews, 9(2), 79-88.

Withrow, K. A., Burton, S., Arnos, K. S., Kalfoglou, A., \& Pandya, A. (2008). Consumer motivations for pursuing genetic testing and their preferences for the provision of genetic services for hearing loss. Journal of Genetic Counseling, 17(3), 252-260.

Yoshinaga-Itano, C. (2003). Early intervention after universal neonatal hearing screening: Impact on outcomes. Mental Retardation and Developmental Disabilities Research Reviews, 9(4), 252-266.

Yoshinaga-Itano C, Abdala de Uzcategui C. (2001). Early identification and social-emotional factors of children with hearing loss and children screened for hearing loss. In: Kurtzer-White E, Luterman D, eds: Early Childhood Deafness. Baltimore, MD: York Press: 13-28.

Yoshinaga-Itano, C., Sedey, A. L., Coulter, D. K., \& Mehl, A. L. (1998). Language of early- and later-identified children with hearing loss. Pediatrics, 102(5), 1161-1171. 